\title{
Analisis Kualiats Pelayanan Tenaga Kependidikan Terhadap Kepuasan Mahasiswa Universitas Buana Perjuangan Karawang ( studi kasus mahasiswa prodi manajemen) CITRA SAVITRI S.E.,M.M.
}

citra.adien@gmail.com

\begin{abstract}
ABSTRAK
Kemajuan sebuah perguruan tinggi salah satunya bergantung pada kompetensi yang dimiliki setiap sumber daya manusianya termasuk tenaga kependidikan. Menjadi perguruan tinggi yang unggul merupakan impian setiap lembaga pendidikan. UBP Karawang yang memiliki 10 Prodi andalan, yang salah satunya adalah Prodi Manajemen dengan jumlah mahasiswa sebanyak 241 yang teregristrasi pada angkatan pertama menjadi pemicu lembaga untuk memberikan pelayanan terbaik agar sesuai harapan dan kebutuhan setiap mahasiswanya. Penelitian ini bertujuan untuk menganalisis tingkat kinerja tenaga kependidikan UBP Karawang terhadap kepuasan yang diterima mahasiswa khususnya mahasiswa prodi manajemen dengan mengumpulkan seluruh informasi yang dibutuhkan lewat kuisioner kepada 100 mahasiswa dengan teknik random sampling dan slovin dengan tingkat kesalahn 7,5\%. Kesimpulan penelitian menunjukkan bahwa berdasarkan tanggapan mahasiswa merasa puas/ memenuhi harapan dari kinerja yang telah dilakukan oleh tenaga kependidikan dalam pelayanan akademik maupun non akademik. Hanya ada 4 butir yang harus diperbaiki dari 17 butir pertanyaan yang diajukan. Butirbutir tersebut antara lain adalah Informasi yang diberikan oleh tenaga kependidikan yang mudah dimengerti dan dipahami, Tenaga kependidikan melayani mahasiswa sejak pertama kali dating, Tenaga kependidikan dapat menanamkan kepercayaan dan rasa aman kepasa mahasiswa dan Tenaga kependidikan selalu menjalankan tugasnya dengan benar dan tepat.
\end{abstract}

KATA KUNCI: Kualitas, Pelayanan, Tenaga Kependidikan, Kepuasan. 


\section{PENDAHULUAN}

Tenaga kependidikan memiliki makna dan cakupan yang jauh lebih luas dari pendidik. Tenaga kependidikan tersebut di samping pendidik, seperti guru, dosen, konselor, pamong belajar, widyaiswara, tutor, instruktur, dan fasilitator, adalah juga termasuk kepala sekolah, direktur, ketua, rektor, pimpinan PLS, penilik, pengawas, peneliti, pengembang bidang pendidikan, pustakawan, laboran, teknisi sumber belajar, penguji dan yang lainnya menurut UU RI No. 20 Tahun 2003 pasal 1 (5) dan (6). Kualifikasi dalam tenaga pendidik adalah tenaga kependidikan yang secara fungsional tugas utamanya secara langsung memberikan pelayanan teknis kependidikan kepada peserta didik. Pelaksanaan tugas pelayanan kependidikan tersebut dapat secara tatap muka secara langsung yang berkaitan dengan kebutuhan akademik. Dalam sebuah Perguruan Tinggi sumber daya merupakan salah satu penentu keberhasilan organisasi. Tenaga kependidikan yang berkualitas dalam memberikan pelayanan mampu memberikan kinerja yang baik bagi organisasi. Dalam proses pelaksanaan kegiatan belajar peran Tenaga Kependidikan sangat berpengaruh terhadap meningkatnya motivasi mahasiswa dalam melaksanakan proses belajar karena mahasiswa dapat dengan mudah untuk mendapatkan informasi yang dibutuhkan selama proses belajar. Tugas yang dilaksanakan tenaga kependidikan antara lain pemberi pelayanan akademik, pemberi informasi akademik, pembuat program akademik dan segala sesuatu yang berkaitan dengan proses kegiatan belajar. Universitas Buana Perjuangan Karawang merupakan salah satu PTS yang ada di Kabupaten Karawang dengan memiliki 10 Program Studi dengan 3 Fakulstas didalamnya yaitu FBIS. FTIK dan FKIP. Pada Fakultas Bisnis dan Ilmu Sosial, Program Studi manajemen merupakan salah satu program studi yang memiliki jumlah mahasiswa terbanyak hal ini dapat dibuktikan pada tabel di bawah :

Tabel 2. Data jumlah mahasiswa pada FBIS 2016

\begin{tabular}{|l|l|l|}
\hline No. & Program Studi & Jumlah Mahasiswa \\
\hline 1. & Manajemen & 241 \\
\hline 2. & Akuntansi & 119 \\
\hline 3. & Psikologi & 121 \\
\hline 4. & Hukum & 102 \\
\hline & Jumlah & $\mathbf{5 7 3}$ \\
\hline
\end{tabular}

Sumber : FBIS 2016 
Universitas Buana Perjuangan Karawang merupakan salah satu perguruan tinggi swasta yang ada di Kabupaten Karawang yang memiliki 10 Program Studi unggulan, salah satunya adalah prodi manajemen. Berdasarkan data diatas maka dapat dilihat bahwa Prodi Manajemen merupakan salah satu prodi yang memiliki jumlah mahasiswa dengan jumlah yang banyak dibanding dengan prodi lain baik di tingkat Fakultas maupun di tingkat Universitas. Hal ini tentunya menjadi salah satu bahan perhatian khusus bagi tenaga kependidikan memberikan pelayanan yang baik guna mendapatkan kepuasan. Pelayanan yang dapat diberikan kepada mahasiswanya antara lain lewat pemenuhan fasilitas yang lengkap, membentuk badan penjaminan mutu, pelatihan para staf pendidik dan tenaga kependidikan dan menyediakan dosen wali untuk membantu mahasiswa dalam keluh kesahnya selama belajar di kampus. Hal tersebut ditentukan dengan strategi yang tepat sesuai dengan situasi dan kondisi pada saat ini, yaitu dengan mengkaji karakteristikkarakteristik pelayanan seperti apa yang dibutuhkan dan diinginkan oleh pelanggannya. Strategi yang tepat akan menghasilkan kualitas pelayanan yang baik pula. Untuk mengetahui bagaimana kualitas pelayanan yang diberikan oleh tenaga kependidikan maka penulis mencoba untuk menganalisa dengan menggunakan tingkat kesesuaian antara harapan dan kepentingan yang diharapkan dapat terciptanya kepuasan yang optimal bagi mahasiswa. Sehubungan dengan hal tersebut maka peneliti melakukan penelitian yang berjudul "Analisis kualiats pelayanan tenaga kependidikan terhadap kepuasan mahasiswa universitas buana perjuangan karawang ( studi kasus mahasiswa prodi manajemen) “ untuk mengukur bagaimana pengaruh berwujud, keandalan, ketanggapan, kepastian dan jaminan yang diberikan tenaga kependidikan dalam upaya memberikan kepuasan kepada mahasiswanya

\section{Rumusan Masalah}

Berdasarkan pemasalah tersebut maka kami mengajukan rumusan masalah yang dapat menjawab permasalah penelitian ini, yaitu:

1. Bagaimana tingkat berwujud pada kualitas pelayanan tenaga kependidikan yang diberikan kepada mahasiswa UBP Karawang ( Studi kasus mahasiswa Prodi Manajemen )?

2. Bagaimana tingkat kehandalan pada kualitas pelayanan tenaga kependidikan yang diberikan kepada mahasiswa UBP Karawang ( Studi kasus mahasiswa Prodi Manajemen )? 
3. Bagaimana tingkat ketanggapan pada kualitas pelayanan tenaga kependidikan yang diberikan kepada mahasiswa UBP Karawang ( Studi kasus mahasiswa Prodi Manajemen )?

4. Bagaimana tingkat jaminan pada kualitas pelayanan tenaga kependidikan yang diberikan kepada mahasiswa UBP Karawang ( Studi kasus mahasiswa Prodi Manajemen )?

5. Bagaimana tingkat empati pada kualitas pelayanan tenaga kependidikan yang diberikan kepada mahasiswa UBP Karawang ( Studi kasus mahasiswa Prodi Manajemen )?

\section{Tujuan Penelitian}

Maksud dan tujuan dilakukan penelitian ini adalah :

1. Untuk mengetahui bagaimana tingkat berwujud pada kualitas pelayanan tenaga kependidikan yang diberikan kepada mahasiswa UBP Karawang ( Studi kasus mahasiswa Prodi Manajemen ) ?

2. Untuk mengetahui bagaimana tingkat kehandalan pada kualitas pelayanan tenaga kependidikan yang diberikan kepada mahasiswa UBP Karawang ( Studi kasus mahasiswa Prodi Manajemen )?

3. Untuk mengetahui bagaimana tingkat ketanggapan pada kualitas pelayanan tenaga kependidikan yang diberikan kepada mahasiswa UBP Karawang ( Studi kasus mahasiswa Prodi Manajemen )?

4. Untuk mengetahui bagaimana tingkat jaminan pada kualitas pelayanan tenaga kependidikan yang diberikan kepada mahasiswa UBP Karawang ( Studi kasus mahasiswa Prodi Manajemen ) ?

5. Untuk mengetahui bagaimana tingkat empati pada kualitas pelayanan tenaga kependidikan yang diberikan kepada mahasiswa UBP Karawang ( Studi kasus mahasiswa Prodi Manajemen ) ?

\section{LANDASAN TEORI}

\section{Pengertian Tenaga Kependidikan}

Tenaga kependidikan adalah anggota masyarakat yang mengabdikan diri dan diangkat untuk menunjang penyelenggaraan pendidikan. (UU No. Ketentuan umum) 20 tahun 2003 pasal 1. Tenaga kependidikan adalah anggota masyarakat yang mengabdikan diri dan diangkat untuk menunjang penyelenggaraan pendidikan. Tugasnya ialah melaksanakan pengawasan dan 
pelayanan teknis untuk menunjang proses pendidikan pada suatu satuan pendidikan. Tenaga kependidikan dapat bekerja secara lintas daerah. Pengangkatan, penempatan, dan penyebaran tenaga kependidikan diatur oleh lembaga yang mengangkat berdasarkan kebutuhan satuan pendidikan formal.

\section{Kualitas Pelayanan}

Supranto (2011) kualitas adalah sebuah kata yang bagi penyedia jasa merupakan sesuatu yang harus dikerjakan dengan baik. Aplikasi kualitas sebagai sifat dari penampilan produk atau kinerja merpakan bagian utama strategi perusahaan dalam rangka meraih keunggulan yang berkesinambungan, baik sebagai pemimpin pasar ataupun strategi untuk terus tumbuh. Menurut Wyckof (dalam Fandy Tjiptono, 2004:59), kualitas layanan adalah tingkat keunggulan yang diharapkan dan pengendalian atas tingkat keunggulan tersebut untuk memenuhi keinginan pelanggan. Ada dua faktor yang mempengaruhi kualitas jasa, yaitu expected service dan perceived service (Fandy Tjiptono 2004:60). Dengan demikian, tingginya tingkat kualitas layanan dapat diukur dengan membandingkan antara expected service dengan perceived service. Fandy Tjiptono, (2004:61) mengatakan harapan pelanggan merupakan keyakinan pelanggan sebelum mencoba atau membeli suatu produk, yang dijadikan standar atau acuan dalam menilai kinerja produk bersangkutan. Setiap konsumen yang berbeda dapat menerapkan tipe ekspektasi yang berbeda untuk situasi yang berbeda.

\section{Mengukur kualitas pelayanan}

Parasuraman dalam studi mengenai SERVQUAL (1988) dalam Fandy Tjiptono (2002:70) berhasil mengidentifikasikan lima kelompok karakteristik yang digunakan pelanggan dalam mengevaluasi kualitas jasa yaitu :

a. Bukti Langsung (Tangibles), yaitu meliputi fasilitas fisik, perlengkapan pegawai dan sarana komunikasi

b. Kehandalan (Reliability), yaitu kemampuasn memberikan pelayanan yang dijanjikan dengan segera, akurat dan memuaskan.

c. Ketanggapan (Responsiveness), yaitu keinginan para staf untuk membantu para pelanggan dan memberikan pelayanan dengan tanggap. 
d. Jaminan dan kepastian (assurance), yaitu mencakup pengetahuan, kemampuan dan kesopanandan sifat dapat dipercaya yang dimiliki para staf, bebas dari bahaya, resiko atau keragu-raguan.

e. Emphati (Emphaty), yaitu kemudahan dalam melakukan hubungan, komunikasi yang baik, perhatian pribadi dan memahami kebutuhan para pelanggan. Dalam penelitian ini menggunakan toeri dimensi kualitas pelayanan dari Parasuraman.

Dimensi kualitas layanan yang dikemukakan oleh para ahli di atas, kemudian dijadikan satu model pengukuran kualitas yang lebih dikenal dengan nama SERVQUAL. Lima dimensi kualitas layanan tersebut dijabarkan lebih lanjut dalam Tabel 2.1.

\section{Tabel 2.1.}

\section{Dimensi dan Atribut Model SERVQUAL}

\begin{tabular}{|l|l|l|}
\hline No & \multicolumn{1}{|c|}{ Dimensi } & \multicolumn{1}{c|}{ Atribut } \\
\hline 1 & Berwujud & $\begin{array}{l}\text { Ruangan yang strategis dan mudah terjangkau } \\
\text { Kebersihan ruangan tenaga kependidikan } \\
\text { Peralatan yang canggih dan modern } \\
\text { Informasi yang diberikan oleh tenaga kependidikan yang mudah } \\
\text { dimengerti dan dipahami }\end{array}$ \\
\hline 2 & Keandalan & $\begin{array}{l}\text { Tenaga kependidikan melayani semua mahasiswa sesuai dengan } \\
\text { janjinya } \\
\text { Tenaga kependidikan memberikan pelayanan yang sama kepada } \\
\text { seluruh mahasiswa } \\
\text { Tenaga kependidikan melayani mahasiswa sejak pertama kali datang }\end{array}$ \\
\hline 3 & Daya Tanggap & $\begin{array}{l}\text { Tenaga kependidikan mengetahui kebutuhan mahasiswa } \\
\text { Tenaga kependidikan melayani dengan cepat dan tepat } \\
\text { Tenaga kependidikan memiliki pengetahuan yang cukup untuk } \\
\text { menjawab setiap pertanyaan dan permasalahan }\end{array}$ \\
\hline 4 & Jaminan & $\begin{array}{l}\text { Tenaga kependidikan dapat menyimpan data dengan benar dan akurat } \\
\text { Tenaga kependidikan dapat menanamkan kepercayaan dan rasa aman } \\
\text { kepada mahasiswa } \\
\text { Tenaga kependidikan selalu menjalankan tugasnya dengan benar dan } \\
\text { tepat } \\
\text { Tenaga kependidikan menjamin kevalidan setiap informasi yang } \\
\text { diberikan }\end{array}$ \\
\hline 5 & Empati & $\begin{array}{l}\text { Tenaga kependidikan bersikap ramah dan sopan } \\
\text { Tenaga kependidikan penuh perhatian dan sabar melayani mahasiswa } \\
\text { Tenaga kependidikan bersikap simpatik terhadap permasalahan } \\
\text { mahasiswa }\end{array}$ \\
\hline
\end{tabular}

Sumber : Fandy Tjiptono, 2004 


\section{KERANGKA BERFIKIR}

Kualitas pelayanan yang baik akan berpenaruh terhadap kepuasan pelanggan. hal tersebut terjadi karena kepuasan merupakan faktor yang sangat menentukan dalam upaya meningkatkan kualitas perusahaan, sebaliknya kekecewaan pelanggan dalam memberikan pelayanan bisa dijadikan kehancuran perusahaan di masa mendatang. Organisasi haarus mampu untuk mempertahankan pelanggan dengan pemberian pelayanan yang optimal. Oleh karena itu dalam memberikan jasa pelayanan organisasi harus dapat memenuhi lima kriteria kualitas pelayanan yaitu daya tangkap, keandalan, jaminan, empati, dan bukti fisik (Parasuraman dkk 1985). Kelima unsur tersebut akan menjadi acuan utama dalam kerangka penelitian ini.

KUALITAS PELAYANAN :

1. BERWUJUD ( Tangible)

2. KEANDALAN ( Realiable)

3. KETANGGAPAN ( Responsivness)

4. KEPASTIAN ( Assurance)

5. Jaminan ( Emphaty)
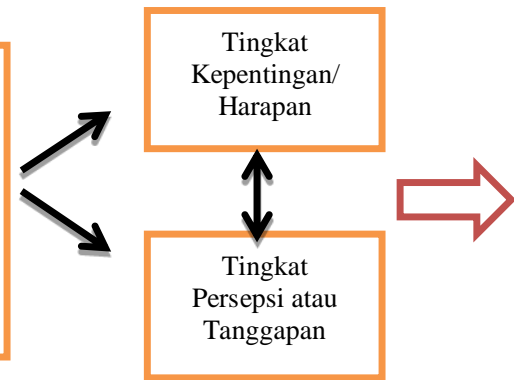

KEPUASAN

\section{Gambar 2.2 Lima Kriteria Kualitas}

Berdasarkan gambar pada kerangka piker diatas maka dapat dilihat bahwa kepuasan yang dapat diberikan kepada konsumen dapat diperoleh ketika kualitas pelayanan mampu dipenuhi Pada penelitian ini, peneliti menggunakan logika matematik dengan melakukan generalisasi serta menggabungkan olahan statistic dengan olahan verbal. Selanjutnya membagi variable penelitian menjadi variable independen dan dependen yang mempunyai hubungan asosiatif, Sugiono (2000:13). Maholtra (1999: 214) menjelaskan tentang konsep of kausality yang menyebutkan bahwa " Causality went the occurrence of X increases the probably of occurrence of $\mathrm{Y}$ ".

\section{PENGUMPULAN DATA}

1. Populasi

Yang menjadi populasi penelitian ini adalah seluruh mahasiswa UBP Karawang Prodi Manajemen angkatan tahun 2015 dengan jumlah 241. 


\section{Sampel}

Data dikumpulkan dengan mengambil sampel secara acak atau random sampling. Teknik sampling menggunakan teknik slovin. Maka sampel nya didapat jika tingkat kesalahnya 7,5\% adalah 100 mahasiswa sebagai responden.

\section{TEKNIK ANALISIS}

Menganalisis data penelitian ini menggunakan metode deskriptif kualitatif kuantitatif. Untuk menjawab perumusan masalah mengenai bagaimana kualitas pelayanan tenaga kependidikan terhadap kepuasan mahasiswa Universitas Buana Perjuangan Karawang (studi kasus mahasiswa prodi manajemen), maka menggunakan Importance-Performance Analysis (Jonh A. Martila and John C. James, 1977) atau analisis kepentingan dan kinerja kepuasan pelanggan.(Supranto, 2011) Dalam hal ini, menggunakan skala likert terdiri dari tingkat kepentingan dan tingkat persepsi yaitu:

1. Tingkat kepentingan diberikan bobot sebagai berikut: (a) Jawaban sangat penting diberi bobot 5; (b) Jawaban penting diberi bobot 4; (c) Jawaban cukup penting diberi bobot 3; (d) Jawaban kurang penting diberi bobot 2; (e) Jawaban tidak penting diberi bobot 1

2. Tingkat Harapan diberikan penilaian dengan bobot sebagai berikut: (a) Jawaban sangat baik diberi bobot 5; (b) Jawaban baik diberi bobot 4; (c) Jawaban cukup baik diberi bobot 3; (d) Jawaban kurang baik diberi bobot 2; (e) Jawabab tidak baik diberi bobot 1 .

Berdasarkan hasil penelitian tingkat kepentingan dan hasil penilaian harapan maka akan dihasilkan suatu perhitungan mengenai tingkat kesesuaian antara tingkat kepentingan dan tingkat pelaksanaannya oleh tenaga kependidikan.

Tingkat kesesuaian adalah sail perbandingan skor kualitas pelayanan (kepentingan) dengan skor kepentingan. Tingkat kesesuaian yang akan menentukan urutan prioritas peningkatan faktor-faktor yang mempengaruhi kualitas pelayanan.

Adapun rumus yang digunakan adalah: $T k i=\frac{X i}{Y i} \times 100 \%$

Dimana $:$ Tki $=$ tingkat kesesuaian responden

$\mathrm{Xi}=$ skor kualitas pelayanan

$\mathrm{Yi}=$ skor penilaian kepuasan mahasiswa

Sumbu mendatar (X) akan diisi oleh skor tingkat kepentingan, sedangkan sumbu tegak (Y) akan diisi oleh skor tingkat kepentingan. Maka akan didapat rumus: 
$\bar{X}=\frac{\sum X i}{n} \quad \bar{Y}=\frac{\sum Y i}{n}$

$\bar{X}=$ skor rata-rata tingkat kepentingan

$\bar{Y}=$ skor rata-rata tingkat harapan

$\mathrm{n}=$ jumlah responden

diagram kartecius merupakan suatu bangun yang dibagi atas empat bagian yang dibatasi oleh dua buah garis yang berpotongan tegak lurus pada titik $(\overline{\bar{X}}, \overline{\bar{Y}}) \cdot \overline{\bar{X}}$ merupakan rata-rata dari rata-rata skor tingkat persepsi mahasiswa seluruh faktor atau atribut dan $\overline{\bar{Y}}$ merupakan rata-rata dari skor rata-rata tingkat kepentingan seluruh faktor atau atribut. Seluruh atribut ada 10 atau $\mathrm{K}=10$ maka selanjutnya rumus.

$\overline{\bar{X}}=\frac{\sum_{i=1}^{n} \overline{X l}}{K} \quad \overline{\bar{Y}}=\frac{\sum_{i=1}^{n} \overline{Y l}}{K}$

$\mathrm{K}$ adalah banyaknya atribut yang dapat mempengaruhi kualitas pelayanan.

Maka digaram kartesiusnya sebagai berikut

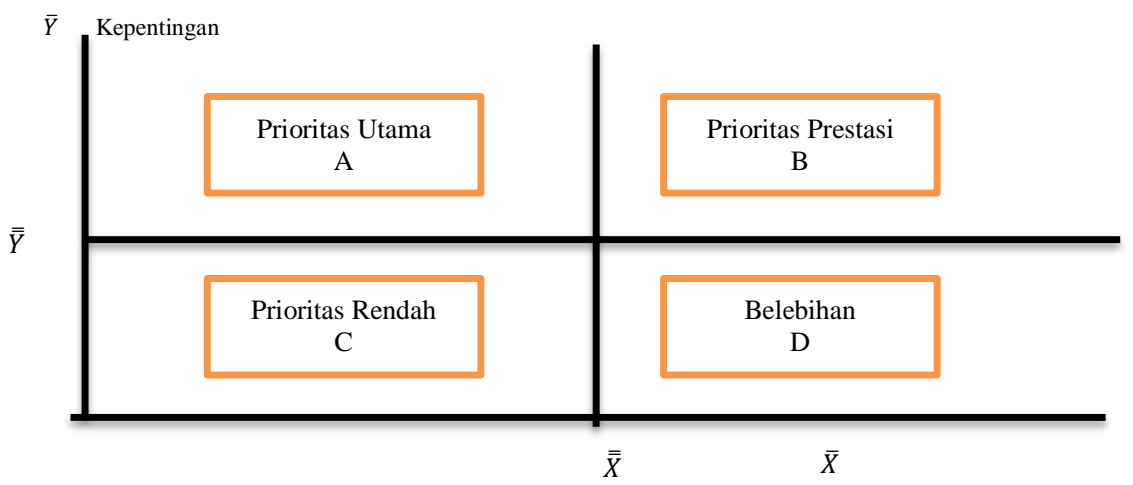

Keterangan:

A. Menunjukan faktor atau atribut yang dianggap mempengaruhi kualitas pelayanan, termasuk unsur-unsur jasa yang diangap penting, namun manajemen belum melaksanakannya sesuai dengan keinginan mahasiswa.

B. Menunjukan unsur jasa pokok yang telah berhasil dilaksanakan tenaga kependidikan , untuk itu wajib dipertahankan.

C. Menunjukan beberapa faktor yang kurang penting pengaruhnya bagi mahasiswa, pelaksanaan bagi tenaga kependidikan biasa-biasa saja.

D. Menunjukan faktor yang mempengaruhi mahasiswa kurang penting akan tetapi pelaksanaanya berlebihan. 


\section{ANALISIS DATA DAN PEMBAHASAN}

\section{Deskripsi Data}

Berdasarkan pengumpulan data yang dilakukan melalui angket penelitian didapatkan data angket sebagai berikut:

Tabel 5.1 Data Kuesioner Mahasiswa

\begin{tabular}{|c|c|c|c|c|c|c|c|c|c|c|c|}
\hline \multirow[b]{2}{*}{ Atribut } & \multirow[b]{2}{*}{ Dimensi } & \multicolumn{5}{|c|}{ Kinerja } & \multicolumn{5}{|c|}{ Kepentingan/Harapan } \\
\hline & & $\begin{array}{c}\text { Sangat } \\
\text { puas }\end{array}$ & Puas & $\begin{array}{c}\text { Cukup } \\
\text { Puas }\end{array}$ & $\begin{array}{c}\text { Kurang } \\
\text { Puas }\end{array}$ & $\begin{array}{l}\text { Tidak } \\
\text { Puas }\end{array}$ & $\begin{array}{r}\text { Sangat } \\
\text { penting }\end{array}$ & Penting & $\begin{array}{l}\text { Cukup } \\
\text { Penting }\end{array}$ & $\begin{array}{l}\text { Kurang } \\
\text { Penting }\end{array}$ & $\begin{array}{c}\text { Tidak } \\
\text { Penting }\end{array}$ \\
\hline 1 & \multirow{5}{*}{ Berwujud } & 3 & 54 & 36 & 4 & 3 & 78 & 22 & 0 & 0 & 0 \\
\hline 2 & & 5 & 58 & 32 & 4 & 3 & 38 & 62 & 0 & 0 & 0 \\
\hline 3 & & 3 & 48 & 37 & 14 & 0 & 56 & 44 & 0 & 0 & 0 \\
\hline 4 & & 0 & 44 & 33 & 23 & 0 & 88 & 12 & 0 & 0 & 0 \\
\hline 5 & & 0 & 45 & 32 & 23 & 0 & 44 & 56 & 0 & 0 & 0 \\
\hline 6 & \multirow{4}{*}{ Keandalan } & 0 & 64 & 30 & 6 & 0 & 55 & 45 & 0 & 0 & 0 \\
\hline 7 & & 0 & 55 & 33 & 11 & 1 & 60 & 40 & 0 & 0 & 0 \\
\hline 8 & & 0 & 57 & 31 & 10 & 2 & 61 & 39 & 0 & 0 & 0 \\
\hline 9 & & 0 & 56 & 33 & 11 & 0 & 45 & 55 & 0 & 0 & 0 \\
\hline 10 & \multirow{2}{*}{$\begin{array}{c}\text { Daya } \\
\text { Tanggap }\end{array}$} & 0 & 68 & 20 & 12 & 0 & 68 & 32 & 0 & 0 & 0 \\
\hline 11 & & 2 & 56 & 34 & 10 & 0 & 57 & 43 & 0 & 0 & 0 \\
\hline 12 & \multirow{3}{*}{ Jaminan } & 3 & 42 & 36 & 14 & 8 & 56 & 44 & 0 & 0 & 0 \\
\hline 13 & & 0 & 41 & 37 & 10 & 12 & 58 & 42 & 0 & 0 & 0 \\
\hline 14 & & 0 & 48 & 38 & 18 & 6 & 55 & 45 & 0 & 0 & 0 \\
\hline 15 & \multirow{3}{*}{ Empati } & 0 & 56 & 32 & 22 & 0 & 46 & 54 & 0 & 0 & 0 \\
\hline 16 & & 0 & 55 & 30 & 12 & 3 & 46 & 54 & 0 & 0 & 0 \\
\hline 17 & & 0 & 57 & 31 & 5 & 7 & 57 & 43 & 0 & 0 & 0 \\
\hline
\end{tabular}

Sumber: Data primer, olah data 2017

Berdasarkan data yang telah diolah diatas maka dapat dihitung tingkat kesesuaiannya yaitu perbandingan hasil kinerja tenaga kependidikan dengan harapan/ kepentingan mahasiswa dalam memperoleh pelayanan yang diberikan oleh tenaga kependidikan. Hasil kuisioner tersebut digunakan untuk menentukan factor-faktor yang mempengaruhi kepuasan mahasiswa terhadap kinerja yang telah diberikan oleh tenaga kependidikan. Uraian tersebut dapat dilihat dari table dibawah ini

Tabel 5.2 Hasil Tingkat Kesuaian Kinerja

\begin{tabular}{|c|l|c|c|c|c|c|c|}
\hline \multirow{2}{*}{ Atribut KETERANGAN } & \multicolumn{5}{|c|}{ Kinerja } & \multirow{2}{*}{ Jumlah } \\
\cline { 3 - 7 } & & 5 & 4 & 3 & 2 & 1 & \\
\hline 1 & Ruangan yang strategis dan mudah terjangkau & 15 & 216 & 108 & 8 & 3 & 350 \\
\hline 2 & Kebersihan ruangan tenaga kependidikan & 25 & 232 & 96 & 8 & 3 & 373 \\
\hline 3 & Peralatan yang canggih dan modern & 15 & 192 & 111 & 28 & 0 & 346 \\
\hline 4 & $\begin{array}{l}\text { Informasi yang diberikan oleh tenaga kependidikan yang } \\
\text { mudah dimengerti dan dipahami }\end{array}$ & 0 & 176 & 99 & 46 & 0 & 321 \\
\hline 5 & $\begin{array}{l}\text { Tenaga kependidikan melayani semua mahasiswa sesuai } \\
\text { dengan janjinya }\end{array}$ & 0 & 180 & 96 & 46 & 0 & 322 \\
\hline 6 & $\begin{array}{l}\text { Tenaga kependidikan memberikan pelayanan yang sama } \\
\text { kepada seluruh mahasiswa }\end{array}$ & 0 & 256 & 90 & 12 & 0 & 358 \\
\hline 7 & $\begin{array}{l}\text { Tenaga kependidikan melayani mahasiswa sejak pertama } \\
\text { kali dating }\end{array}$ & 0 & 220 & 99 & 22 & 1 & 342 \\
\hline 8 & Tenaga kependidikan mengetahui kebutuhan mahasiswa & 0 & 228 & 93 & 20 & 2 & 343 \\
\hline 9 & Tenaga kependidikan melayani dengan cepat dan tepat & 0 & 224 & 99 & 22 & 0 & 345 \\
\hline 10 & $\begin{array}{l}\text { Tenaga kependidikan memiliki pengetahuan yang cukup } \\
\text { untuk menjawab setiap pertanyaan dan permasalahan }\end{array}$ & 0 & 272 & 60 & 24 & 0 & 356 \\
\hline
\end{tabular}


Analisis Kualiats Pelayanan Tenaga Kependidikan Terhadap Kepuasan Mahasiswa Universitas Buana Perjuangan Karawang ( studi kasus mahasiswa prodi manajemen)

\begin{tabular}{|c|l|c|c|c|c|c|c|}
\hline 11 & $\begin{array}{l}\text { Tenaga kependidikan dapat menyimpan data dengan benar } \\
\text { dan akurat }\end{array}$ & 10 & 224 & 102 & 20 & 0 & 356 \\
\hline 12 & $\begin{array}{l}\text { Tenaga kependidikan dapat menanamkan kepercayaan dan } \\
\text { rasa aman kepada mahasiswa }\end{array}$ & 15 & 168 & 108 & 28 & 8 & 312 \\
\hline 13 & $\begin{array}{l}\text { Tenaga kependidikan selalu menjalankan tugasnya dengan } \\
\text { benar dan tepat }\end{array}$ & 0 & 164 & 111 & 20 & 12 & 307 \\
\hline 14 & $\begin{array}{l}\text { Tenaga kependidikan menjamin kevalidan setiap informasi } \\
\text { yang diberikan }\end{array}$ & 0 & 192 & 114 & 36 & 6 & 378 \\
\hline 15 & Tenaga kependidikan bersikap ramah dan sopan & 0 & 224 & 96 & 44 & 0 & 364 \\
\hline 16 & $\begin{array}{l}\text { Tenaga kependidikan penuh perhatian dan sabar melayani } \\
\text { mahasiswa }\end{array}$ & 0 & 220 & 90 & 24 & 3 & 337 \\
\hline 17 & $\begin{array}{l}\text { Tenaga kependidikan bersikap simpatik terhadap } \\
\text { permasalahan mahasiswa }\end{array}$ & 0 & 228 & 93 & 10 & 7 & 338 \\
\hline
\end{tabular}

Sumber: Hasil oleh data primer, 2017.

\section{Tabel 5.3. Tingkat Hasil Kepentingan/ Harapan}

\begin{tabular}{|c|c|c|c|c|c|c|c|}
\hline \multirow[b]{2}{*}{ Atribut } & \multirow[b]{2}{*}{ KETERANGAN } & \multicolumn{5}{|c|}{ Kepentingan / Harapan } & \multirow{2}{*}{ Jumlah } \\
\hline & & 5 & 4 & 3 & 2 & 1 & \\
\hline 1 & Ruangan yang strategis dan mudah terjangkau & 390 & 88 & 0 & 0 & 0 & 478 \\
\hline 2 & Kebersihan ruangan tenaga kependidikan & 190 & 248 & 0 & 0 & 0 & 438 \\
\hline 3 & Peralatan yang canggih dan modern & 280 & 176 & 0 & 0 & 0 & 456 \\
\hline 4 & $\begin{array}{l}\text { Informasi yang diberikan oleh tenaga kependidikan yang } \\
\text { mudah dimengerti dan dipahami }\end{array}$ & 440 & 48 & 0 & 0 & 0 & 488 \\
\hline 5 & $\begin{array}{l}\text { Tenaga kependidikan melayani semua mahasiswa sesuai } \\
\text { dengan janjinya }\end{array}$ & 220 & 224 & 0 & 0 & 0 & 444 \\
\hline 6 & $\begin{array}{l}\text { Tenaga kependidikan memberikan pelayanan yang sama } \\
\text { kepada seluruh mahasiswa }\end{array}$ & 275 & 180 & 0 & 0 & 0 & 455 \\
\hline 7 & $\begin{array}{l}\text { Tenaga kependidikan melayani mahasiswa sejak pertama kali } \\
\text { dating }\end{array}$ & 300 & 160 & 0 & 0 & 0 & 460 \\
\hline 8 & Tenaga kependidikan mengetahui kebutuhan mahasiswa & 305 & 156 & 0 & 0 & 0 & 461 \\
\hline 9 & Tenaga kependidikan melayani dengan cepat dan tepat & 225 & 220 & 0 & 0 & 0 & 445 \\
\hline 10 & $\begin{array}{l}\text { Tenaga kependidikan memiliki pengetahuan yang cukup } \\
\text { untuk menjawab setiap pertanyaan dan permasalahan }\end{array}$ & 340 & 128 & 0 & 0 & 0 & 468 \\
\hline 11 & $\begin{array}{l}\text { Tenaga kependidikan dapat menyimpan data dengan benar dan } \\
\text { akurat }\end{array}$ & 285 & 172 & 0 & 0 & 0 & 457 \\
\hline 12 & $\begin{array}{l}\text { Tenaga kependidikan dapat menanamkan kepercayaan dan } \\
\text { rasa aman kepada mahasiswa }\end{array}$ & 280 & 176 & 0 & 0 & 0 & 456 \\
\hline 13 & $\begin{array}{l}\text { Tenaga kependidikan selalu menjalankan tugasnya dengan } \\
\text { benar dan tepat }\end{array}$ & 290 & 168 & 0 & 0 & 0 & 458 \\
\hline 14 & $\begin{array}{l}\text { Tenaga kependidikan menjamin kevalidan setiap informasi } \\
\text { yang diberikan }\end{array}$ & 275 & 180 & 0 & 0 & 0 & 455 \\
\hline 15 & Tenaga kependidikan bersikap ramah dan sopan & 230 & 216 & 0 & 0 & 0 & 446 \\
\hline 16 & $\begin{array}{l}\text { Tenaga kependidikan penuh perhatian dan sabar melayani } \\
\text { mahasiswa }\end{array}$ & 230 & 216 & 0 & 0 & 0 & 446 \\
\hline 17 & $\begin{array}{l}\text { Tenaga kependidikan bersikap simpatik terhadap } \\
\text { permasalahan mahasiswa }\end{array}$ & 285 & 172 & 0 & 0 & 0 & 457 \\
\hline
\end{tabular}

Sumber: Hasil oleh data primer, 2017.

\section{Analisis Kinerja dan Kepentingan/ Harapan}

\subsubsection{Dimensi Berwujud}

\section{Butir 1. Ruangan yang strategis dan mudah terjangkau}

Pada butir ini menjelaskan tentang bukti fisik ruangan yang strategis dan mudah dijangkau oleh mahasiswa. Tingkat kesesuaian dari kedua data tersebut yaitu: $=\frac{350}{478} \times 100 \%=73,22 \%$ 


\section{Butir 2. Kebersihan ruangan tenaga kependidikan}

Pada butir ini menjelaskan tentang kebersihan ruangan tenaga kependidikan. Tingkat kesesuaian dari kedua data tersebut yaitu: $=\frac{373}{438} \times 100 \%=85,15 \%$

Butir 3. Peralatan yang canggih dan modern

Kemudahan dalam pencarian informasi dan dapat dipahami dari tenaga kependidikan . Tingkat kesesuaian dari kedua data tersebut yaitu : : $=\frac{346}{456} \times 100 \%=75,87 \%$

Butir 4. Informasi yang diberikan oleh tenaga kependidikan yang mudah dimengerti dan dipahami

Kemampuan tenaga kependidikan dalam menyampaikan jasa sesuai dengan waktu yang dijanjikan tentunya akan berdampak baik bagi kepuasan yang akan diperoleh mahasiswa terhadap pelayanan yang telah diberikan. Keandalan tersebut sangat membantu mahasiswa agar termotivasi untuk melaksanakan setiap aturan yang telah ditentukan. Tingkat kesesuaian dari kedua data tersebut yaitu: $=\frac{321}{488} \times 100 \%=65,77 \%$

\subsubsection{Dimensi Keandalan}

\section{Butir 5. Tenaga kependidikan melayani semua mahasiswa sesuai dengan janjinya}

Keandalan tenaga kependidikan dalam menyimpan setiap dokumen/ catatan tanpa merupakan hal penting yang harus dilakukan. Tingkat kesesuaian dari kedua data tersebut yaitu : : = $\frac{322}{444} \times 100 \%=72,52 \%$

Butir 6. Tenaga kependidikan memberikan pelayanan yang sama kepada seluruh mahasiswa

Kemampuan tenaga kependidikan dalam memberikan informasi tentang kepastian waktu dalam penyampaian jasa tentunya sangat berpengaruh terhadap masalah yang mungkin dihadapi oleh mahasiswa. Tingkat kesesuaian dari kedua data tersebut yaitu: $=\frac{358}{455} \times 100 \%=78,68 \%$

\section{Butir 7.Tenaga kependidikan melayani mahasiswa sejak pertama kali datang}

Ketanggapan tenaga kependidikan dalam memberikan layanan dengan segera/ cepat bagi setiap mahasiswa memiliki peran penting, karena pemberian layanan tersebut akan mempermudah proses 
akademik dalam lembaga tersebut. Tingkat kesesuaian dari kedua data tersebut yaitu: = $\frac{342}{460} \times 100 \%=74,3 \%$

\subsubsection{Dimensi Daya Tanggap}

\section{Butir 8. Tenaga kependidikan mengetahui kebutuhan mahasiswa}

Kemampuan tenaga kependidikan dalam membantu mahasiswa merupakan salah satu motivator bagi mahasiswa dan mempermudah proses akademik mahasiswa. Tingkat kesesuaian dari kedua data tersebut yaitu: $=\frac{343}{461} \times 100 \%=74,4 \%$

\section{Butir 9. Tenaga kependidikan melayani dengan cepat dan tepat}

Kesiapan tenaga kependidikan untuk merespon setiap permintaan mahasiswa dapat menjadi tolak ukur kompetensi yang dimiliki tenaga kependidikan dan mempermudah proses berjalannya kegiatan belajar dan kebutuhan akademik mahasiswa tersebut. Tingkat kesesuaian dari kedua data tersebut yaitu: $=\frac{345}{445} \times 100 \%=77,52 \%$

Butir 10. Tenaga kependidikan memiliki pengetahuan yang cukup untuk menjawab setiap pertanyaan dan permasalahan

Menumbuhkan rasa percaya, sopan dan aman dalam setiap melakukan transaksi atau kegiatan dengan mahasisw merupak hal yang sulit, namun ketika tenaga kependidkan mampu untuk memenuhinya artinya akan berdampak pada kepuasan yang akan diterima setiap mahasiswa dan berpengaruh pada proses akademik secara baik dan berkualitas.

Tingkat kesesuaian dari kedua data tersebut yaitu: $=\frac{356}{468} \times 100 \%=76,06 \%$

\subsubsection{Dimensi Jaminan}

Butir 11. Tenaga kependidikan dapat menyimpan data dengan benar dan akurat

Setiap mahasiswa tentunya memiliki hak yang sama dalam medapatkan setiap informasi yang berkaitan tentang akademik maupun non akademik. Kemampuan tenaga kependidikan dalam menjawab setiap pertanyaan mahasiswa akan mempermudah mahasiswa dalam mendapatkan informasi yang diperlukan. Tingkat kesesuaian dari kedua data tersebut yaitu: $=\frac{356}{457} \times 100 \%=$ $77,89 \%$

Butir 12. Tenaga kependidikan dapat menanamkan kepercayaan dan rasa aman kepada mahasiswa 
Sikap empati tenaga kependidikan dalam memberikan perlakuan mahasiswa secara penuh perhatian tentunya merupakan bagian dari pelayanan yang harus dipenuhi ketika mahasiswa membutuhkan informasi. Tingkat kesesuaian dari kedua data tersebut yaitu: $=\frac{312}{456} \times 100 \%=$ $68,42 \%$

\section{Butir 13. Tenaga kependidikan selalu menjalankan tugasnya dengan benar dan tepat}

Setiap mahasiswa memiliki hak yang sama untuk mendapatkan informasi yang berkaitan dengan akademik maupun non akademik, kesungguhan setiap tenaga kependidikan dalam membantu mahasiswa yang membutuhkan setiap informasi akan sangat berpengaruh pada peningkatakan prestasi setiap mahasiswa. Hal ini dapat ditunjukkan dari tingkat kesesuaian dari kedua data tersebut yaitu $=\frac{307}{458} \times 100 \%=67,03 \%$

\section{Butir 14. Tenaga kependidikan menjamin kevalidan setiap informasi yang diberikan}

Setiap mahasiswa mempunyai kebutuhan akan informasi yang berkaitan dengan akademik dan non akademik yang sama. Kemampuan tenaga kependidikan dalam memahami setiap kebutuhan mahasiswa merupakan salah satu hal penting agar proses kegiatan belajar dapat berjalan dengan baik. Tingkat kesesuaian dari kedua data tersebut yaitu $=\frac{378}{455} \times 100 \%=83,07 \%$

\subsubsection{Dimensi Empati}

\section{Butir 15. Tenaga kependidikan bersikap ramah dan sopan}

Peralatan yang modern merupakan salah satu faktor pemting yang sangat mendukung tenaga kependidikan dalam memberikan layanan prima kepada setiap mahasiswa. Hal ini sangat dirasa penting karena dengan pemenuhan peralatan yang modern akan mempermudah dalam memberikan setiap informasi yang dibutuhkan dan memperkecil human eror dalam setiap masalah yang terjadi. Tingkat kesesuaian dari kedua data tersebut yaitu $=\frac{364}{446} \times 100 \%=81,61 \%$

\section{Butir 16. Tenaga kependidikan penuh perhatian dan sabar melayani mahasiswa}

Fasilitas kampus yang berdaya tarik visual merupakan salah satu strategi yang dapat diberikan tenaga kependidikan dalam memberikan layanan sehingga menimbulkan rasa nyaman dan puas bagi setiap mahasiswa Fasilitas tersebut menjadi poin penting dari pandangan awal atas pelayanan lembaga pendidikan. Tingkat kesesuaian dari kedua data tersebut yaitu $=\frac{337}{446} \times 100 \%=75,56 \%$

\section{Butir 17. Tenaga kependidikan bersikap simpatik terhadap permasalahan mahasiswa}

Salah satu hal penting yang perlu diperhatian dalam memberikan layanan adalah penampilan yang rapi. Hal tersebut tentunya akan berdampak pada kenyamanan setiap mahasiswa dalam 
memperoleh setiap kebuituhan yang diinginkan secara langsung dengan nyaman. Maka setiap tenaga kependidikan wajib menjaga kerapihan baik dalam penampilan secara fisik. Tingkat kesesuaian dari kedua data tersebut yaitu $=\frac{338}{457} \times 100 \%=73,96 \%$

\section{Diagram Kartesius}

Berdasarkan dari hasil analsiis yang telah dilakukan, penelitian menunjukkan bahwa kualitas pelayanan tenaga kependidikan terhadap kepuasan mahasiswa tertera dalam empat bagian pada diagram kartesius, sebagai berikut

Tabel 5.4. Perhitungan Rata-rata penilaian kepentingan dan harapan pelayanan tenaga kependidikan dalam diagram kartesius

\begin{tabular}{|c|c|c|c|c|}
\hline No & Kinerja & Kepentingan/ Harapan & $\bar{X}$ & $\bar{Y}$ \\
\hline 1 & 350 & 478 & 3,50 & 4,78 \\
\hline 2 & 373 & 438 & 3,73 & 4,38 \\
\hline 3 & 346 & 456 & 3,46 & 4,56 \\
\hline 4 & 321 & 488 & 3,21 & 4,88 \\
\hline 5 & 322 & 444 & 3,22 & 4,44 \\
\hline 6 & 358 & 455 & 3,58 & 4,55 \\
\hline 7 & 342 & 460 & 3,42 & 4,60 \\
\hline 8 & 343 & 461 & 3,43 & 4,61 \\
\hline 9 & 345 & 445 & 3,45 & 4,45 \\
\hline 10 & 356 & 468 & 3,56 & 4,68 \\
\hline 11 & 356 & 457 & 3,56 & 4,57 \\
\hline 12 & 312 & 456 & 3,12 & 4,56 \\
\hline 13 & 307 & 458 & 3,07 & 4,58 \\
\hline 14 & 378 & 455 & 3,78 & 4,55 \\
\hline 15 & 364 & 446 & 3,64 & 4,46 \\
\hline 16 & 337 & 446 & 3,37 & 4,46 \\
\hline \multirow[t]{2}{*}{17} & 338 & 457 & 3,38 & 4,57 \\
\hline & Rata- rata & & 3,44 & 4,56 \\
\hline
\end{tabular}

Sumber: Olah data primer, 2017

Hasil analisis data yang diperoleh saat melaksanakan penelitian menunjukkan bahwa kualitas pelayanan tenaga kependidikan terhadap kepuasaan mahasiswa tertera pada diagram berikut ini

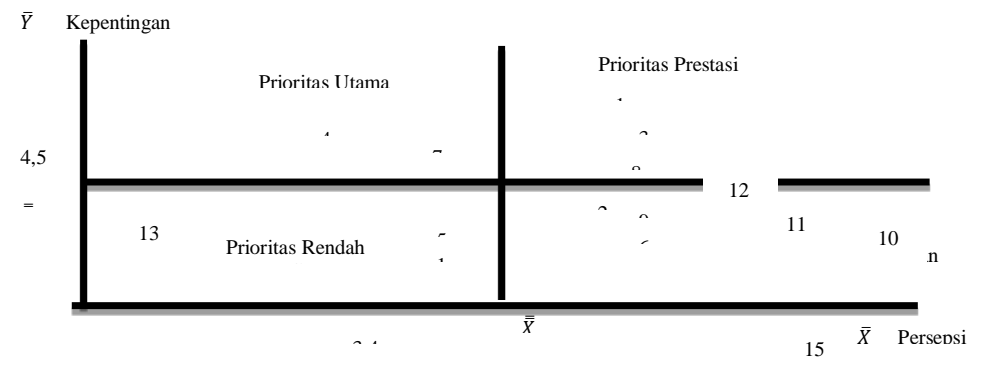

Gambar 5.1 Diagram Kartesius

Sumber: Olah data primer, 2017 


\section{PEMBAHASAN}

Berdasarkan dari hasil penelitian yang telah dilakukan dan diukur berdasarkan tingkat kepentingan dan harapan/ kepuasan yang diinginkan menunjukkan bahwa kinerja yang diberikan tenaga kependidikan dapat mempertimbangkan setiap usaha yang dapat diperbaiki dan dianggap penting oleh setiap mahasiswa yang digambarkan lewat diagram kartesius pada gambar 4.1 melalui uraian sebagai berikut :

1. Kuadran A

Pada kuadran ini menunjukan faktor pelayanan yang perlu diprioritaskan oleh tenaga kependidikan dalam memberikan pelayanan, karena pada faktor ini dinilai sangat penting, sedangkan tingkat pelaksanaannya masih belum memuaskan. Variable yang masuk dalam kuadran A adalah :

1. Butir 4. Informasi yang diberikan oleh tenaga kependidikan yang mudah dimengerti dan dipahami

2. Butir 7. Tenaga kependidikan melayani mahasiswa sejak pertama kali datang

3. Butir 12. Tenaga kependidikan dapat menanamkan kepercayaan dan rasa aman kepasa mahasiswa

4. Butir 13. Tenaga kependidikan selalu menjalankan tugasnya dengan benar dan tepat

\section{Kuadran B}

Pada kuadran ini menunjukkan factor pelayanan yang perlu dipertahankan oleh tenaga kependidikan karena pelaksanaanya telas sesuai dengan kepentingan dan harapan/kepuasan mahasiswa. Variabel yang masuk kedalam kuadran ini adalah :

1. Butir 1. Ruangan yang strategis dan mudah terjangkau

2. Butir 3. Peralatan yang canggih dan modern

3. Butir 8. Tenaga kependidikan mengetahui kebutuhan mahasiswa

4. Butir 10. Tenaga kependidikan memiliki pengetahuan yang cukup untuk menjawab setiap pertanyaan mahasiswa

5. Butir 11. Tenaga kependidikan dapat menyimpan data dengan benar dan akurat 
3. Kuadran $\mathrm{C}$

Pada kuadran ini menunjukan bahwa faktor pelayan masih dianggap kurang penting bagi mahasiswa. Sedangkan pelaksanaan pelayanan yang diberikan dianggap cukup. Variabel yang masuk kedalam kuadran $\mathrm{C}$ adalah :

1. Butir 5. Tenaga kependidikan melayani semua mahasiswa dengan janjinya

2. Butir 16. Tenaga kependidikan penuh perhatian dan sabar melayani mahasiswa

4. Kuadran D

Pada kuadran ini menunjukan bahwa faktor pelayanan yang diberikan tenaga kependidikan dinilai berlebihan dalam pelaksanaan. Mahasiswa menganggap pelayanan yang diberikan kurang penting sedangkan pelaksanaan pelayanan sangat baik. Variabel yang masuk kedalam kuadran D adalah :

1. Butir 2. Kebersihan ruangan tenaga kependidikan

2. Butir 6. Tenaga kependidikan memberikan pelayanan yang sama kepada seluruh mahasiswa

3. Butir 9. Tenaga kependidikan melayani dengan cepat dan tepat

4. Butir 14. Tenaga kependidikan menjamin kevalidan setiap informasi yang diberikan

5. Butir 15. Tenaga kependidikan bersikap ramah dan sopan

6. Butir 17. Tenaga kependidikan bersikap simpatik terhadap permasalahan mahasiswa

\section{KESIMPULAN \& SARAN}

\section{KESIMPULAN}

Berdasarkan analisis dan pembahasan yang telah dilakukan maka hasil penelitian yang dapat peneliti simpulkan adalah pelayanan yang telah dilaksanakan tenaga kependidikan telah sesuai dengan harapan yang diinginkan setiap mahasiswa, terbukti dari setiap butir yang telah dianalisis bahwa mahasiswa puas terhadap keandalan, daya tanggap, kepastian, jaminan dan empati dapat mewakili dari setiap dimensi. Diantaranya adalah kemampuan dalam memberikan jasa yang benar, kesediaan membantu mahasiswa jika mengalami masalah baik yang berkaitan dengan akademik maupun non akademik, kemampuan dalam menjawab setiap pertanyaan dan materi yang disampaikan mampu menarik perhatian mahasiswa lewat visual. Namun demikian ada beberapa hal yang harus menjadi perhatian dan perbaikan bagi tenaga kependidikan dalam meningkatkan 
kinerjanya terutama dalam ketepatan dalam memberikan jasa sesuai dengan yang telah dijanjikan, pemberian layanan dengan segera,kesungguhan dan mengutamakan dalam memperhatikan mahasiswa.

\section{SARAN}

Dari kesimpulan yang telah dibuat maka peneliti memberikan saran sebagai berikut :

1. Setiap tenaga kependidikan diberikan pelatihan yang berkaitan dengan kemampuan memberikan pelayanan/ jasa pada pelanggan

2. Pemberian kuisioner kepada setiap pelanggan untuk dapat mengukur tingkat kinerja yang dilaksanakan sehingga dengan mudah bagi pemberi jasa dalam melakukan perbaikan dan peningkatan

3. Mempertahankan apa yang telah dilaksanakan sehingga kepuasan yang telah didapat akan terus terjaga sehingga mampu untuk melakukan peningkatan kearah yang lebih baik

4. Adakan forum diskusi antara tenaga kependidikan dan mahasiswa agar sama-sama memiliki 1 persepsi dan tujuan untuk membangun perguruan tinggi menjadi lebih baik.

5. Meningkatkan fasilitas yang ada dengan tujuan untuk mempermudah setiap mahasiswa maupun tenaga kependidikan dalam melaksanakan proses kegiatan baik informasi yang berkaitan dengan akademik maupun non akademik 


\section{DAFTAR PUSTAKA}

Amins, Achmad. 2009. Manajemen Kinerja Pemerintah daerah. Yogyakarta: LaksBang Mangkunegara, Anwar Prabu. 2007. Evaluasi Kinerja Sumber Daya Mnausia Perusahaan. Bandung: Refika Aditama

J. Supranto. 2011. Pengukuran tingkat kepuasan pelanggan. Jakarta: Rineka Cipta

Kirom, Bahrul. 2013. Mengukur Kinerja Pelayanan dan Kepuasan Konsumen cetakan 3. Bandung: Pustaka Reka cipta

Kotler, Phillip. 1995. Marketing Management Analysis, Planning, Implementation\& Control.

Prentice Hall Int,Kreitner, Robert and Angelo Kinicki. 2010. Organizational Behavior.

New York: McGraw-Hill

Kotler, Philip. 1994. Marketing Manajemen:Analisys, Planning, Implementation \& Control.

Prentice Hall International Editions: Eighth Edition

McShane, Steven L. And Mary Ann Von Glinoe. 2006. Worley. Built to change. San Francisco: John Wiley \& Sons, Inc.

Miftah Thoha. 2003 , Kepemimpinan Dalam Manajemen Jakarta : PT. Raja Grafindo Persada.

Nasution,S, 1996, Metode Penelitian Naturastik Kualitatif, Tarsito, Bandung. Parasuman, Zeithaml,V.A, A.A.Berry,L.L,1995, Delivering Service Qualitiy : Balancing Cumtomer Perceptions and Expectation, The Free Press,New York.

Parasuraman, A; Zeithaml, V.A; and Berry, L.L., 1985. A Conceptual Model of Sevice Quality and its Implications for Future Research. Jurnal of Marketing (fall)

Riana, Nurhelda. 2013. Analisis Kinerja Pegawai Dalam Pelaksanaan Pelayanan Publik di Puskesmas Maridan Kecamatan Sepaku Kabupaten Penajam Paser Utara. E-Jurnal Ilmu Pemerintahan Universitas Mulawarman.

Robbin, Stephen P. And Timonthy A. Judge. 2011. Organizational Behavior. New Jersey: Pearson Education. Inc.

Salehudin ,1999, Pengaruh Kualitas Jasa Terhadap Loyalitas Pelanggan, Universitas Brawijaya Malang.

Suprapto, J.2001. Pengukuran Tingkat Kepuasan Pelanggan. Edisi Baru. PT. Rineka Cipta, Jakarta. 
Sari Aida, Evaluasi Kepuasan Nasabah atas Layanan Perbankan Berbasis Banking, Network

( Studi Kasus pada Bank BCA Cabang Bandar Lampung ). Jurnal Bisnis dan Manajemen, Vol 3 No.1, Bandar lampung.

Tjiptono, Fandi. 2004. Strategi Pemasaran, edisi kedua. Yogyakarta: Andi Ofset

Thomas Stefanus Kaihatu. 2008. Analisis kesenjangan kualitas pelayanan dan kepuasan konsumen pengunjung Plasa Tanjung Surabaya. Surabaya: Jurnal Ekonomi Manajemen, Fakultas Ekonomi Universitas Kristen Petra Vol 10 no 1.

Valerie Zeithaml, Mary Jo Bitner, Dwayne D. Gremler . 2006. Services Marketing. Mc Graw Hill. New York.

Wibowo. 2013. Perilaku dalam organisasi. Jakarta: Raja grafindo persada 